\title{
Divergent Interest Rates in the Theory of Financial Markets*
}

\author{
Lutz Kruschwitz ${ }^{\mathrm{a}}$, Andreas Löffler ${ }^{\mathrm{a}, *}$, Daniela Lorenz ${ }^{\mathrm{b}}$ \\ ${ }^{a}$ Institute of Banking and Finance, Freie Universität Berlin, Thielallee 73, 14195 Berlin, \\ Germany \\ ${ }^{b}$ Chair of Business Administration and Corporate Finance, \\ Julius-Maximilians-Universität Würzburg, Sanderring 2, 97070 Würzburg, Germany
}

\begin{abstract}
We extend models of financial markets by incorporating divergent riskfree interest rates for borrowing and deposits. Divergent interest rates create arbitrage opportunities if each market participant is allowed both to borrow and lend money. In our model, we circumvent such arbitrage opportunities by allowing only one institution to act as a bank (granting risk-free credits and financial investments). The surplus of this bank has to be redistributed to the market participants.

Assuming only one risky asset we show that - while not necessarily unique - an equilibrium always exists. We investigate the relation to a financial markets equilibrium based on a unique interest rate being intuitively determined as a (weighted) average from borrowing and deposit rate. We provide proof that this unique interest rate approximately generates correct asset prices only if every investor trades, the bank's proceeds are distributed equally among investors and the number of investors is rather large. Otherwise severe mispricings may result.
\end{abstract}

Keywords:

Asset Pricing, Portfolio Choice, Divergent Borrowing and Deposit Rates JEL: G11, G12

\footnotetext{
${ }^{\star}$ We thank the participants in presentations at Brandenburgische Technische Universität Cottbus, at Julius-Maximilians-Universität Würzburg, at Griffith University (Brisbane) as well as participants of a doctoral seminar at Freie Universität Berlin for helpful comments.

${ }^{*}$ Corresponding author

Email address: AL@WACC.de (Andreas Löffler)
} 


\section{Problem}

Every theory of a financial market is based on a number of simplifying assumptions. In particular, one often assumes that a unique risk-free rate applies to both depositing and borrowing activities. No one would dispute that a unique risk-free rate is an assumption verging on the ridiculous, yet this is the typical case discussed in the literature. Even textbooks very seldom mention a model with divergent interest rates 11 We will introduce divergent borrowing and deposit rates and look at the consequences for market equilibrium. The prevailing response to what would change if we renounce a unique $r_{f}$ would be: "not much". We will show that in general this answer is wrong and only holds under a very particular set of assumptions.

Also, such an insight is by no means obvious. As already Hirshleifer (1958) observed classical results from the Fisher model do break down if the interest rate is not unique. So, it is rather surprising that no one has posed the question as to whether something similar would happen if in a financial market model (for example, the Capital Asset Pricing Model or CAPM) borrowing and depositing is carried out with different interest rates.

One reason why divergent interest rates have not sufficiently been investigated might be due to the following fact. Every equilibrium theory requires a consistent modelling. If, however, each investor is permitted to grant risk-free credit in a framework with divergent interest rates, one could become infinitely rich simply by founding a financial institution and approving credit at a higher rate than the interest rate which applies to a financial investment. Such arbitrage opportunities clearly cripple any capital market model fundamentally since they are by no means reconcilable with an equilibrium. Any attempt to derive equilibrium prices is foredoomed to failure because it becomes unclear how supply and demand can be balanced. From a theoretical point of view, our paper contributes to prior literature by explicitly creating an arbitrage-free environment that allows for a consistent equilibrium modelling.

There is another aspect that makes our approach particularly interesting. In a typical Arrow-Debreu setup an equilibrium is characterized by two conditions: markets clear and each investor maximizes their utility, regardless of what other investors are doing. Our modelling will imply that the

\footnotetext{
${ }^{1}$ In a former edition of the Brealey/Myers textbook divergent interest rates are mentioned as one form of market imperfection. Interestingly, the authors state "Having glimpsed the problems of imperfect markets, we shall, like an economist in a shipwreck, simply assume our life jacket and swim safely to shore", Brealey and Myers (1996, p. 24).
} 
second condition will not be enough to characterize an equilibrium. Rather, the action of other investors will influence the trading options of each investor. This resembles more of a Nash than an Arrow-Debreu equilibrium. We have to accept that consistent modelling also requires a different equilibrium concept for an exchange economy.

We believe that most economists do not consider an equilibrium with divergent interest rates to be very different from an equilibrium with a unique risk-free rate $r_{f}$. In particular, one would expect that prices with a single $r_{f}$ are more or less equal to prices with divergent rates if $r_{f}$ is chosen to be a (weighted) average of both deposit and borrowing rates. Using a simple example we will show that this intuition is incorrect. If both interest rates are to be merged into one unique rate, this rate may be quite different from the original rates.

It is possible to develop our ideas in a general exchange equilibrium. But we believe that a capital market equilibrium in which we can derive closed-form solutions allows for a more distinct way of presenting our results. Therefore, we have opted for an equilibrium with $\mu-\sigma$ utility functions having constant absolute risk aversion (i.e. a CAPM).

In the next section we explain how no-arbitrage in the context of divergent interest rates can be ensured and provide a literature review that identifies research gaps. The following section formulates the model, derives the results and compares them to the traditional financial market model. In particular, we discuss the following questions: How can we formulate a capital asset pricing model with divergent interest rates that rules out arbitrage? How can an equilibrium in such a framework be defined? Does an equilibrium exist, and (with appropriate assumptions) is it unique? What kind of relationship exists between such an equilibrium and a traditional equilibrium with unique interest rates? The last section provides a summary.

\section{The literature}

Prior research in the context of models under certainty revealed that the relaxation of this assumption has a significant impact on the results. E.g., as far as the Fisher mode 2 is concerned it can be shown that investors' initial endowments as well as their consumption preferences can influence their investment decisions if deposit and borrowing rates do not coincide 3

\footnotetext{
${ }^{2}$ See Fisher (1930).

${ }^{3}$ See Hirshleifer (1958).
} 
However, in equilibrium models under uncertainty, such as the neoclassical capital asset pricing mode 4 rather few such considerations exist.

In order to prevent our model being subject to arbitrage opportunities we build on an idea that has already been proposed by Cheng (1980). In the presence of divergent interest rates, he states that "it is no longer feasible for the investors to lend and borrow from one another. However this can be handled by letting a 'bank' enter the loan market, or by letting brokerage firms perform the tasks of granting security loans and/or taking deposits." 5 This is exactly what is assumed throughout our paper: We will allow only one institution to carry out the granting of risk-free credits and financial investments. This institution shall be called "bank" ${ }^{6}$ Our problem is not completely solved at this stage, because a difficulty arises that has been neglected so far: Following Cheng (1980), the bank pockets the difference between credit and debit rates. But what happens to that surplus?

A similar issue is well known from equilibrium models with taxes: In this case, the Treasury collects taxes and ends up with a surplus as well. In many models this surplus is not returned to the taxpayers ${ }^{7}$ This circumstance is hardly compatible with an equilibrium model where we are obliged to consider the entire market and cannot perform a local analysis. The few papers that explicitly take into account a redistribution of the tax surplus to the taxpayers show that this might change the main statements of the model 8 We cannot at all rule out a similar influence on the results if we look at divergent interest rates. Therefore, in order to develop a coherent model, the cash surplus of the bank should not vanish into thin air but should be redistributed in full to the market participants. Thus, the crucial part of our approach is not the existence of a bank per se, but the bank's redistribution of proceeds among the investors. To the best of our knowledge, such a redistribution has never been complied with in the relevant literature.

The first and most important paper dealing with divergent interest rates in context of the CAPM is Brennan (1971). While he derives some properties of capital market equilibrium, neither the inherent arbitrage nor a

\footnotetext{
${ }^{4}$ See Sharpe (1964), Lintner $(1965)$ and Mossin $(1966)$.

${ }^{5}$ See Cheng 1980 p. 513).

${ }^{6}$ Note that the model allows the bank to consist of a network of several branch offices and subsidiaries that consolidate all their cash surpluses. However, the existence of private (profit maximizing) banks is excluded from our model.

${ }^{7}$ See Brennan (1970) or Litzenberger and Ramaswamy (1979).

${ }^{8}$ See e.g., Kruschwitz and Löffler (2009), Eikseth and Lindset (2009), Konrad (1991) and Sialm (2009).
} 
redistribution of the interest spread proceeds are discussed. Nevertheless, Brennan (1971) forms the basis for several further studies. All studies that build on Brennan, though, do not alter the main setup of the model and in particular are not able to solve the inherent problem of an arbitrage opportunity when borrowing and deposit rates are not the same. We therefore refer this literature to a footnote 9

\section{Model}

\subsection{Setup}

In this paper we focus on the appropriate modelling of divergent interest rates. Hence, we will simplify aspects which we believe are of no particular relevance. In particular, we will assume that investors have utilities with constant absolute risk aversion (CARA) because this will enable us to establish simple solutions. Furthermore, we will only discuss the case of one risky asset and postpone the debate of a market with several risky assets to a follow-up paper 10

We start with investors $i=1, \ldots, I$ who trade in a capital market with only one risky asset. We assume a one-period model and the absence of short selling restrictions. The risky asset shall be arbitrarily divisible, is priced $S_{0}$ in $t=0$, and generates a risky payment in $t=1$ amounting to $S_{1} 11$ Without loss of generality we assume $S_{0}>0$. However, investors form homogeneous expectations $\mathrm{E}\left(S_{1}\right)$ and know the variance $\operatorname{Var}\left(S_{1}\right)$ of the asset's future payments. Each investor is initially endowed with $\bar{n}_{i}$ shares of the risky asset. We designate the sum of the initial endowments as the market portfolio $\bar{n}$. The investor's task is to determine the optimal quantity of risky assets $n_{i}$ and to adjust his initial portfolio accordingly.

\footnotetext{
9 Davis et al. (2006) expand the model to a multi-period setting and show that (unlike Brennan) higher borrowing costs can raise the demand for equity. Chua (1975) criticized Brennan's argumentation, but was unable to shake his main result. Cheng (1980) pointed out that Brennan's research question had been empirically motivated and started to discuss the topic of divergent interest rates analytically. Above all, he wanted to find out how to value risky assets "when various forms of financial restrictions and loan market imperfections are introduced to the CAPM," see Cheng (1980, p. 509). The paper of Bamberg and Firchau (1981) also ties directly to Brennan (1971). Hammami (2014) finally wants to investigate how the implications of the Brennan-paper should be adressed in empirical tests using the Fama-MacBeth, the Shanken, and the Kan-Robotti-Shanken $t$-statistics.

${ }^{10}$ With multiple risky assets complexity arises due to correlations among the assets. In order to understand the underlying mechanisms in closed-form solutions we restrict our analysis of the optimal demand and equilibrium to the case of solely one risky asset.

${ }^{11}$ Dividends can easily be integrated in the model but do not provide any further insights.
} 
If the available budget is insufficient to finance the optimal portfolio, the investor has to borrow money. If, in contrast, the portfolio does not require the investor's whole initial endowment, she makes a risk-free investment. Note, however, that there is no risk-free asset in the market. Instead each market participant can make use of a risk-free borrowing and risk-free deposit opportunity. For simplicity, the payments of such transactions in $t=1$ are standardized at one monetary unit.

We will presume that the interest rate for risk-free borrowing $\left(r^{\mathrm{b}}\right)$ and the rate for risk-free deposits $\left(r^{\mathrm{d}}\right)$ do not necessarily have to coincide. Instead we allow the borrowing rate to exceed the deposit rate, $r^{\mathrm{b}} \geq r^{\mathrm{d}}{ }^{12}$ The price of one credit contract in $t=0$ then amounts to $\frac{1}{1+r^{\mathrm{b}}}$, whereas a risk-free financial investment costs $\frac{1}{1+r^{\mathrm{d}}} \cdot n_{i}^{\mathrm{b}}$ denotes the number of credit contracts an investor $i$ signs. $n_{i}^{\mathrm{d}}$ designates the number of risk-free investment contracts. In $t=1$ the investor liquidates all risky assets for the purpose of consumption. Also she receives the payments of her risk-free investment or pays back the credit obligation including interest, neither of which are subject to any uncertainty. The notation is summarized in Figure 1.

Figure 1: Notation

\begin{tabular}{lc|c|c} 
& & $t=0$ & $t=1$ \\
\hline \multirow{2}{*}{ risky asset } & price & $S_{0}$ & $S_{1}$ \\
& endowment & $\bar{n}_{i}$ & \\
& optimal quantity & $n_{i}$ & \\
\hline \multirow{2}{*}{ riskless investment } & price & $\frac{1}{1+r^{\mathrm{d}}}$ & 1 \\
& endowment & 0 & \\
\hline \multirow{3}{*}{ riskless boworring } & primal quantity & $n_{i}^{\mathrm{d}}$ & \\
& optimal quantity held & $n_{i}^{\mathrm{b}}$ &
\end{tabular}

Note, that the investor cannot choose negative risk-free quantities,

$$
n_{i}^{\mathrm{b}}, n_{i}^{\mathrm{d}} \geq 0 \text {. }
$$

\footnotetext{
${ }^{12} \mathrm{~A}$ scenario with negative interest rates on deposits is discussed at the end of this section.
} 
Also, in optimum they will not be positive at the same time since raising credit and simultaneous risk-free investing at the lower interest rate cannot be advantageous,

$$
n_{i}^{\mathrm{b}} \cdot n_{i}^{\mathrm{d}}=0 .
$$

Without any further assumptions, we would have to deal with the aforementioned arbitrage opportunity: by founding a financial institution, any investor could give credit at a higher rate than the interest rate which applies to a financial investment that is necessary to finance the credit. Our model avoids arbitrage by allowing only one specific institution to carry out this kind of financial business - this "bank" is the only authority that is permitted to grant both, credits and financial investments without risk. There is no endowment with financial resources of the bank. If the bank generates a cash surplus, these funds will be redistributed to the investors according to a previously agreed upon distribution rule.

In order to formulate the individual maximization problem in detail we have to take a closer look at this redistribution. Since we assume that in equilibrium ${ }^{13}$ the bank does not grant more credit than the received amount of financial investments, the following must hold for the cash balance in $t=0$ ("zero-net supply condition"),

$$
0=\sum_{i=1}^{I}\left(\frac{n_{i}^{\mathrm{d}}}{1+r^{\mathrm{d}}}-\frac{n_{i}^{\mathrm{b}}}{1+r^{\mathrm{b}}}\right) .
$$

From $r^{\mathrm{b}} \geq r^{\mathrm{d}}$ it follows that $0 \geq \sum_{i}\left(n_{i}^{\mathrm{d}}-n_{i}^{\mathrm{b}}\right)$, meaning no fewer credit contracts are being signed than financial investment contracts. At date $t=1$ the bank pays off its investors and receives the redemption and interest payments from its debtors. This necessarily yields a cash surplus of

$$
\sum_{i=1}^{I}\left(n_{i}^{\mathrm{b}} \cdot 1-n_{i}^{\mathrm{d}} \cdot 1\right) \geq 0
$$

which is redistributed to the investors according to a certain rule. The $i$ th investor receives a deterministic share $\omega_{i} \geq 0$ of the entire surplus from the bank, whereby these shares sum up to one or $\sum_{i=1}^{I} \omega_{i}=1$. If we

\footnotetext{
${ }^{13}$ We will define an equilibrium in subsection 3.3 .1 .

${ }^{14}$ If we allowed $\omega_{i}$ to be random variables, then any equilibrium could be explained, see Kruschwitz and Löffler (2009, p. 173). Therefore, we believe that it is reasonable to assume deterministic $\omega_{i}$.
} 
wish to attain a special income distribution, the shares $\omega_{i}$ can be selected accordingly.

Uncertain future consumption of the $i$-th investor is denoted by $C_{1 i}$. All market participants derive their portfolio decision on individual CARA utility functions based on expectation and variance 15

$$
U_{i}\left(\mathrm{E}\left(C_{1 i}\right), \operatorname{Var}\left(C_{1 i}\right)\right)=\mathrm{E}\left(C_{1 i}\right)-\frac{a_{i}}{2} \cdot \operatorname{Var}\left(C_{1 i}\right) .
$$

Investors are thus assumed to be unsaturated and risk-averse with an investorspecific coefficient of risk aversion, $a_{i}>0$.

Recently, investors in many major economies experienced negative riskfree rates on their savings $\left(r^{\mathrm{d}}<0\right)$. We have to discuss the implications on investors' optimal demand for the risky asset and market clearance.

We will show that the smaller the deposit rate, the higher will be the demand for risky assets (see below equation (6)). However, if the deposit rate becomes negative, the optimal demand necessarily equals investors' initial endowment, and a balanced situation can only be achieved in form of a no-trade equilibrium. The reason lies in the zero-net supply condition (3): For negative deposit rates any investor who wants to make risk-free savings would prefer holding cash (free of interest) rather than making a risk-free investment at the bank where savings will shrink in time. Consequently, the bank does not receive any funds and the zero net supply condition will only be met if no credit is granted to other investors. Nevertheless, investors who want to purchase additional shares of the risky asset, depend on credit financing since our model allows for no other funding possibilities. However, due to zero net supply, this funding possibility is no longer available, and the investor necessarily has to keep the initial endowment of the risky asset constant. Analogously, if an investor prefers to sell parts of the initial endowment, she would no longer find buyers. Thus, markets only clear in a no-trade equilibrium. Therefore, in the following we will focus on positive interest rates, $r^{\mathrm{b}}, r^{\mathrm{d}}>0$.

Finally, we assume that the asset is traded in a perfect market and that no transaction costs, taxes or market entry barriers are incurred.

\subsection{Individual Maximization Problem}

We have moved the calculation of the optimal demand function to Appendix A. There, we show that in contrast to the capital market model

\footnotetext{
${ }^{15}$ These utility functions are typically for the Capital Asset Pricing Model. An axiomatization of these utility functions can be found in Löffler (1996).
} 
with a unique interest rate, the following cases have to be distinguished depending on the investor's initial endowment.

Investor is $\begin{cases}\text { borrower if } & \bar{n}_{i} \leq n_{i}^{\mathrm{b}} \text { and demands } n_{i}^{\mathrm{b}}=\frac{\mathrm{E}\left(S_{1}\right)-S_{0}\left(1+r^{\mathrm{b}}\right)\left(1-\omega_{i}\right)}{a_{i} \operatorname{Var}\left(S_{1}\right)} \\ \text { depositer if } & \bar{n}_{i} \geq n_{i}^{\mathrm{d}} \text { and demands } n_{i}^{\mathrm{d}}=\frac{\mathrm{E}\left(S_{1}\right)-S_{0}\left(1+r^{\mathrm{d}}\right)\left(1-\omega_{i}\right)}{a_{i} \operatorname{Var}\left(S_{1}\right)} \\ \text { no-trader if } & n_{i}^{\mathrm{b}}<\bar{n}_{i}<n_{i}^{\mathrm{d}} \text { and keeps initial endowment const. }\end{cases}$

This optimal demand is illustrated in Figure 2, It becomes obvious that the optimal demand for the risky assets is decreasing in its current price $S_{0}$. Also, the shape of the function is intuitive: If the price is rather low, the investor demands a high quantity and will therefore enlarge her portfolio which she is initially endowed with. In order to finance this enlargement she borrows funds from the bank. For moderate prices, the investor prefers to refrain from trading and keeps her initial endowment constant. If, by contrast, the current price is rather high, it is optimal for the investor to sell parts of her initial endowment. The proceeds will be invested and the investor consequently acts as a depositer. Thus, with increasing $S_{0}$ the investor becomes a borrower, a no-trader and finally a depositer. The demand function is a continuous and monotonic (but not strictly monotonic) function.

Figure 2: Optimal demand of the risky asset depending on price $S_{0}$.

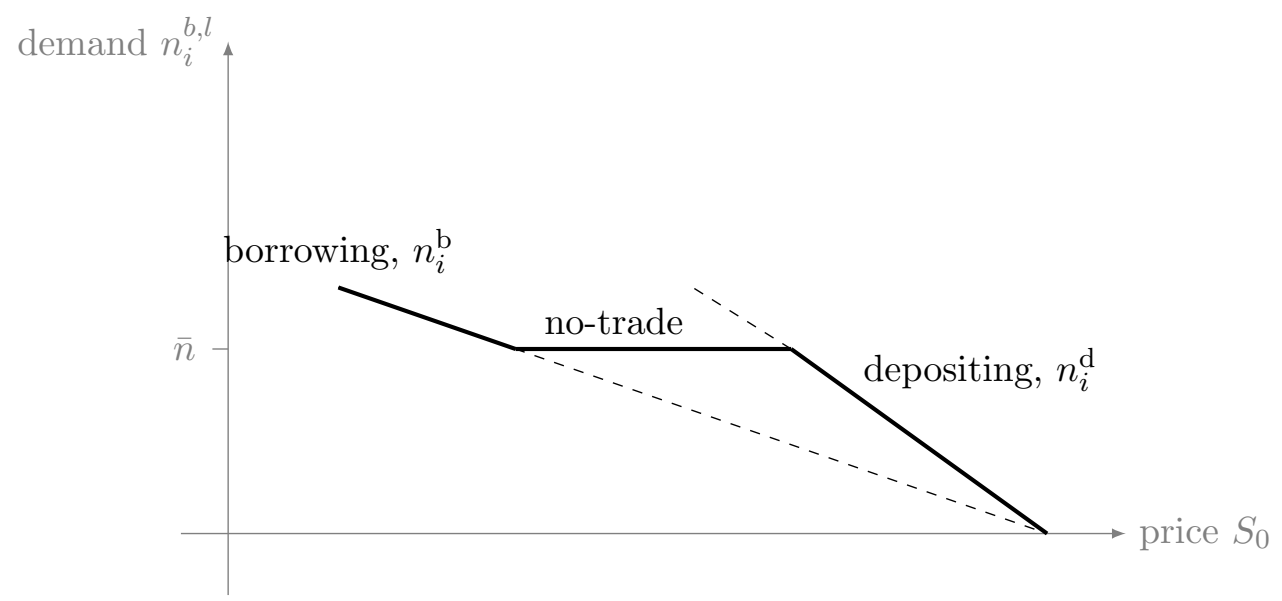

Non-participation in capital markets has been named a stylized fact of household finance. It is well known that a large proportion of investors hold 
no equity ${ }^{16}$ We do not attempt to explain this puzzle but still want to investigate how our parameters influence the decision not to trade. Therefore, we will perform a comparative static.

A closer look at (6) reveals that each investor will demand a positive quantity $n_{i}>0$ as long as the expected return of the risky asset $E(r)$ exceeds the borrowing rate $r^{\mathrm{b}}$. This results from

$$
\begin{aligned}
n_{i}=\frac{\mathrm{E}\left(S_{1}\right)-S_{0}\left(1+\max \left(r^{\mathrm{b}}, r^{\mathrm{d}}\right)\right)\left(1-\omega_{i}\right)}{a_{i} \operatorname{Var}\left(S_{1}\right)} & >0 \\
\frac{\mathrm{E}\left(S_{1}\right)}{S_{0}} \frac{1}{1-\omega_{i}} & >1+r^{\mathrm{b}} \\
\frac{1+E(r)}{1-\omega_{i}} & >1+r^{\mathrm{b} .}
\end{aligned}
$$

Even if $\omega_{i}$ equals 0 for a specific market participant, this investor will thus unfold a positive demand for the risky asset if $E(r)>r^{\mathrm{b}}$. An increasing share in the bank's surplus $\omega_{i}>0$ will further raise the demand for equity.

The no-trading area is mainly influenced by five parameters: the endowment, the share of bank's surplus, the risky asset, the interest rates and the risk aversion,

$$
\text { no trade } \Longleftrightarrow \frac{\mathrm{E}\left(S_{1}\right)-\bar{n}_{i} a_{i} \operatorname{Var}\left(S_{1}\right)}{S_{0}\left(1-\omega_{i}\right)} \in\left[1+r^{\mathrm{d}}, 1+r^{\mathrm{b}}\right]
$$

From this relationship it is evident how these parameters influence the decision of the investor to abstain from trading. We will later consider a numerical example that illustrates this relationship.

\subsection{Equilibrium Analysis}

\subsubsection{Definition}

In a classical Arrow-Debreu equilibrium, prices are defined as such that investors maximize their utility and supply equals demand. In particular, investors choose their optimal portfolio regardless of what the other market participants do. In our model the situation is different.

If one investor chooses to deviate from her optimal portfolio this will have an impact on her borrowing or depositing decision. This in turn influences the bank's surplus that will be distributed to the investors. But then, her

\footnotetext{
${ }^{16}$ See Hirshleifer et al. (2017).
} 
own optimal decision might be different. In contrast to the Arrow-Debreu equilibrium concept, decisions of the investors are connected. This resembles more of a Nash equilibrium where this connection is particularly addressed. This leads us to the following definition, which is distinct from the classical exchange equilibrium.

Definition 1. An equilibrium consists of a set of optimal demand $n_{i}$ and an equilibrium price $S_{0}$ such that the following two conditions are satisfied:

1. For every investor $i$ the demand $n_{i}$ is optimal, given the other investors have chosen their optimal demand.

2. Aggregate supply equals aggregate demand.

Although we will apply this definition from now on, it raises interesting questions that we will not pursue here. For example, one could ask whether a cooperative solution that is different from our case is possible: Investors could stipulate to choose a non-optimal demand in order to have lower or higher redistribution. It is not immediately clear whether such a "bargaining solution" is subgame perfect and whether investors have an incentive to deviate from the contract. We will leave those questions unanswered here.

\subsubsection{Existence}

Markets clear if all demand functions (6) add up to the aggregate endowment $\sum_{i} \bar{n}_{i}$. This requires

$$
\begin{aligned}
\sum_{\text {borrower } i} \frac{\mathrm{E}\left(S_{1}\right)-S_{0}\left(1+r^{\mathrm{b}}\right)\left(1-\omega_{i}\right)}{a_{i} \operatorname{Var}\left(S_{1}\right)}+\sum_{\text {depositer } i} \frac{\mathrm{E}\left(S_{1}\right)-S_{0}\left(1+r^{\mathrm{d}}\right)\left(1-\omega_{i}\right)}{a_{i} \operatorname{Var}\left(S_{1}\right)} \\
+\sum_{\text {no-trader } i} \bar{n}_{i}=\sum_{i} \bar{n}_{i}
\end{aligned}
$$

and this equation can be further simplified to

$$
S_{0}=\frac{\mathrm{E}\left(S_{1}\right) \sum_{\text {trader } i} \frac{1}{a_{i}}-\operatorname{Var}\left(S_{1}\right) \sum_{\text {trader } i} \bar{n}_{i}}{\left(1+r^{\mathrm{b}}\right) \sum_{\text {borrower } i} \frac{1-\omega_{i}}{a_{i}}+\left(1+r^{\mathrm{d}}\right) \sum_{\text {depositer } i} \frac{1-\omega_{i}}{a_{i}}} .
$$

At first glance, this equation looks like a closed-form solution. But this first impression is wrong. The equilibrium price $S_{0}$ determines whether an investor is a borrower, depositer or does not trade at all. Hence, $(9)$ is in fact a fixed-point equation.

Fortunately, it is straightforward to show that such an equilibrium altogether exists. The individual demand is monotonically decreasing and 
continuous in $S_{0}$. This is also true for the aggregate demand. For very large $S_{0}$ the aggregate demand in (8) will be negative and therefore smaller than the aggregate supply $\sum_{i} \bar{n}_{i}$. On the other hand, for small $S_{0}$ the aggregate demand will be very large and therefore higher than aggregate supply. According to the intermediate value theorem ${ }^{17}$ there must exist a solution in which demand and supply are equal.

Since the individual demand functions are monotonically decreasing, the equilibrium is unique unless $S_{0}$ is in a no-trade region of every investor. In this case, no trade will occur and the price $S_{0}$ itself is merely a construction of thought rather than a result of economic activity. This situation is depicted for a market with only two investors in Figure 3 .

Figure 3: The Case of a no-Trade Equilibrium

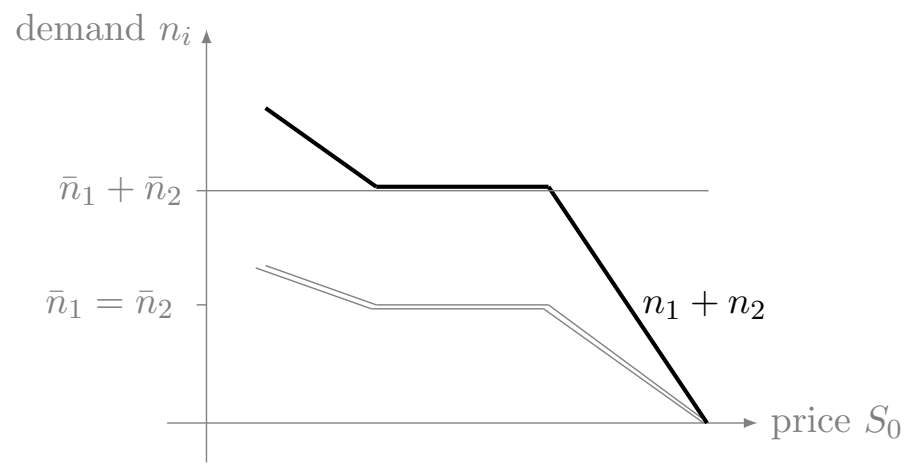

\subsubsection{Relation to the Case of a Unique Risk-Free Rate}

We now want to investigate how our solution differs from the case of a unique interest rate. This interest rate shall be denoted by $r^{*}$.

It is reasonable to assume that our model with divergent interest rates can easily be replaced by a model with a unique interest rate $r^{*}$ when $r^{*}$ is equal to the weighted average of the borrowing rate $r^{\mathrm{b}}$ and deposit rate $r^{\mathrm{d}}$. However, this assumption is false as will be illustrated in a numerical example in the following subsection.

For the following, we prove a theorem that describes the relationship between the divergent interest rates $r^{\mathrm{b}}, r^{\mathrm{d}}$ and the unique rate $r^{*}$. It can be shown that in a classical CARA equilibrium every investor holds the amount of risky assets that corresponds to her risk aversion. Precisely, for

${ }^{17}$ See for example Rudin $\sqrt{1976}$, pp. 42, 93). 
a unique interest rate her optimal demand for the risky asset would amount to a fixed share $H_{i}$ in the market portfolio $\bar{n}$. If the investor's risk tolerance is $a_{i}^{-1}$, then this share is defined as the investor's share of risk tolerance in the aggregate risk tolerance 18 ,

$$
H_{i}:=\frac{a_{i}^{-1}}{\sum_{i} a_{i}^{-1}} .
$$

These coefficients add up to 1 over all trading investors, i.e., $\sum_{j} H_{j}=1$. We can now prove the following theorem.

Theorem 1. The following relationship between divergent interest rates $r^{b}$, $r^{d}$ and a unique interest rate $r^{*}$ holds true

$$
\begin{aligned}
\left(1+r^{b}\right) \sum_{\text {borrower } i}\left(1-\omega_{i}\right) H_{i} & +\left(1+r^{d}\right) \sum_{\text {depositer } i}\left(1-\omega_{i}\right) H_{i}+ \\
& +\sum_{\text {no-trader } i}\left(1+r^{i}\right)\left(1-\omega_{i}\right) H_{i}=\left(1+r^{*}\right) .
\end{aligned}
$$

Proof. The theorem can be shown as follows. From equation (6) we learn that investors prefer to refrain from trading if

$$
\frac{\mathrm{E}\left(S_{1}\right)-S_{0}\left(1+r^{\mathrm{b}}\right)\left(1-\omega_{i}\right)}{a_{i} \operatorname{Var}\left(S_{1}\right)} \leq \bar{n}_{i} \leq \frac{\mathrm{E}\left(S_{1}\right)-S_{0}\left(1+r^{\mathrm{d}}\right)\left(1-\omega_{i}\right)}{a_{i} \operatorname{Var}\left(S_{1}\right)} .
$$

Thus, according to the intermediate value theorem there must exist a rate $r^{i} \in\left(r^{\mathrm{d}}, r^{\mathrm{b}}\right)$ such that

$$
\frac{\mathrm{E}\left(S_{1}\right)-S_{0}\left(1+r^{i}\right)\left(1-\omega_{i}\right)}{a_{i} \operatorname{Var}\left(S_{1}\right)}=\bar{n}_{i}
$$

Plugging this into the equilibrium condition (8) yields

$$
\begin{gathered}
\sum_{\text {borrower } i} \frac{\mathrm{E}\left(S_{1}\right)-S_{0}\left(1+r^{\mathrm{b}}\right)\left(1-\omega_{i}\right)}{a_{i} \operatorname{Var}\left(S_{1}\right)}+\sum_{\text {depositer } i} \frac{\mathrm{E}\left(S_{1}\right)-S_{0}\left(1+r^{\mathrm{d}}\right)\left(1-\omega_{i}\right)}{a_{i} \operatorname{Var}\left(S_{1}\right)}+ \\
+\sum_{\text {no-trader } i} \frac{\mathrm{E}\left(S_{1}\right)-S_{0}\left(1+r^{i}\right)\left(1-\omega_{i}\right)}{a_{i} \operatorname{Var}\left(S_{1}\right)}=\bar{n} .
\end{gathered}
$$

\footnotetext{
${ }^{18}$ This can be shown by plugging in the equilibrium price into the investor's optimal demand function under the assumption of a unique interest rate. See e.g., Bertomeu and Cheynel (2016, p.225-226).
} 
In contrast, the equilibrium in case of a unique interest rate $r^{*}$ is characterized by

$$
\sum_{i} \frac{\mathrm{E}\left(S_{1}\right)-S_{0}\left(1+r^{*}\right)}{a_{i} \operatorname{Var}\left(S_{1}\right)}=\bar{n}
$$

Both equilibrium situations are identical, if and only if

$$
\begin{gathered}
\sum_{\text {borrower } i} \frac{\mathrm{E}\left(S_{1}\right)-S_{0}\left(1+r^{\mathrm{b}}\right)\left(1-\omega_{i}\right)}{a_{i} \operatorname{Var}\left(S_{1}\right)}+\sum_{\text {depositer } i} \frac{\mathrm{E}\left(S_{1}\right)-S_{0}\left(1+r^{\mathrm{d}}\right)\left(1-\omega_{i}\right)}{a_{i} \operatorname{Var}\left(S_{1}\right)} \\
+\sum_{\text {no-trader } i} \frac{\mathrm{E}\left(S_{1}\right)-S_{0}\left(1+r^{i}\right)\left(1-\omega_{i}\right)}{a_{i} \operatorname{Var}\left(S_{1}\right)}=\sum_{i} \frac{\mathrm{E}\left(S_{1}\right)-S_{0}\left(1+r^{*}\right)}{a_{i} \operatorname{Var}\left(S_{1}\right)}
\end{gathered}
$$

which can be further simplified,

$$
\begin{aligned}
\left(1+r^{\mathrm{b}}\right) \sum_{\text {borrower } i} \frac{1-\omega_{i}}{a_{i}}+ & \left(1+r^{\mathrm{d}}\right) \sum_{\text {depositer } i} \frac{1-\omega_{i}}{a_{i}}+ \\
& +\sum_{\text {no-trader } i} \frac{\left(1+r^{i}\right)\left(1-\omega_{i}\right)}{a_{i}}=\left(1+r^{*}\right) \sum_{i} \frac{1}{a_{i}}
\end{aligned}
$$

Finally, applying the definition of $H_{i}$ completes the proof.

According to our theorem, $\left(1+r^{*}\right)$ appears to be a weighted average of $\left(1+r^{\mathrm{b}}\right),\left(1+r^{\mathrm{d}}\right)$ as well as $\left(1+r^{i}\right)\left(\right.$ which ranges between $\left(1+r^{\mathrm{b}}\right)$ and $\left.\left(1+r^{\mathrm{d}}\right)\right)$. Note, however, that the weights $\left(1-\omega_{i}\right) H_{i}$ do not add up to 1 and thus lack economic interpretation. Nevertheless, our theorem enables us to consider a special case that highlights the relationship between the interest rates and allows an interpretation as weighted average under certain conditions. To this end, let us assume that firstly, every investor trades and secondly, every investor receives the same redistribution, $\omega_{i}=\frac{1}{I}$.

Theorem 2. If every investor trades and if every investor receives the same redistribution, then

$$
1+r^{*}=\left(\left(1+r^{b}\right) b+\left(1+r^{d}\right)(1-b)\right) \frac{I-1}{I},
$$

where $b=\sum_{\text {borrowers } i} H_{i}$ is the proportion of the risky asset held by the borrowers and $(1-b)$ the proportion of the risky asset held by the depositers.

Approximately, this is

$$
r^{*} \approx r^{\mathrm{b}} b+r^{\mathrm{d}}(1-b)-\frac{1}{I}
$$


Obviously, the unique interest rate $r^{*}$ is approximately indeed a weighted average of the divergent interest rates, if $\frac{1}{I}$ is sufficiently small. This leads to the conclusion that in the case of divergent interest rates, a financial market model based on a unique interest rate can only generate correct asset prices $S_{0}$, if everyone trades, if the bank's proceeds are distributed equally among investors and if the number of investors is large.

\subsubsection{Numerical Example}

In order to illustrate how (or to which extent) divergent risk-free interest rates change the demand for risky assets, we provide the following numerical example.

Assume there are three investors in the market that aim to optimize their demand for the risky asset. This asset has an expected future payment amounting to $\mathrm{E}\left(S_{1}\right)=10$, the variance of the payment is $\operatorname{Var}\left(S_{1}\right)=1$. The investor-specific parameters are summarized in Figure 4.

Figure 4: Example: Investor-specific parameters

\begin{tabular}{l|ccc} 
& investor 1 & investor 2 & investor 3 \\
\hline risk aversion $a_{i}$ & 1 & 1 & 40 \\
share $\omega_{i}$ & 0.1 & 0 & 0.90 \\
risky endowment $\bar{n}_{i}$ & 1 & 1 & 1
\end{tabular}

Let us first consider an exchange economy with divergent interest rates. Accordingly, it is possible to borrow money from the bank at a $r^{\mathrm{b}}=10 \%$ rate, while the interest rate on risk-free investments is only $r^{\mathrm{d}}=5 \% 19$ We will later show that $S_{0}=8.3113$ turns out to be the equilibrium price. In this economy investors' optimal demand results in the numbers as shown in the first row of Figure $5^{20}$

\footnotetext{
${ }^{19}$ For purposes of presentation, we chose rather high interest rates. Realworld interest rates are published by federal banks, e.g. for Germany https: //www.bundesbank.de/Navigation/DE/Statistiken/Zeitreihen_Datenbanken/Geld_ und_Kapitalmaerkte/geld_und_kapitalmaerkte_node.html?nodeToClose=1193166

${ }^{20}$ See Appendix B for the calculation. Obviously, the optimal demand differs between the three investors as there are differences in their risk aversion parameters, initial endowments and shares in the banks' redistribution of cash surplus.
} 
Figure 5: Example: Optimal demand of the risky asset.

\begin{tabular}{l|rrr}
\multicolumn{1}{c|}{ economy } & \multicolumn{3}{|c}{ optimal risky demand } \\
& investor 1 & investor 2 & investor 3 \\
\hline with divergent interest rates & 1.7718 & 1.0000 & 0.2282 \\
with interest rate $7.5 \%, S_{0}=8.3113$ & 1.0654 & 1.0654 & 0.0266 \\
with interest rate $7.5 \%, S_{0}=7.9242$ & 1.4815 & 1.4815 & 0.0370 \\
with interest rate $2.4933 \%, S_{0}=8.3113$ & 1.4815 & 1.4815 & 0.0370
\end{tabular}

The current price of $S_{0}=8.3113$ obviously clears the market, since aggregate demand equals aggregate supply,

$$
\begin{aligned}
\sum_{i=1}^{3} n_{i} & =\sum_{i=1}^{3} \bar{n}_{i} \\
1.7718+1.0000+0.2282 & =1+1+1 .
\end{aligned}
$$

If we consider an economy with the same asset price amounting $S_{0}=$ 8.3113 but, in contrast, with a unique interest rate amounting to $7.5 \%$ the optimal demand for the three investors is presented in the second row of Figure $5^{21}$ However, in this scenario markets do not clear because the aggregate demand $(1.0654+1.0654+0.0266)$ does not equal aggreagte supply $(1+1+1)$.

In order to obtain an equilibrium with a unique interest rate, the asset price $S_{0}$ must adjust. The resulting equilibrium price that clears the market amounts to $S_{0}=7.9242$ and is therefore different from the equilibrium price above. The optimal demand for the risky asset as shown in the third row of Figure 5 is different compared to the economy with divergent risk-free rates since the bank can no longer generate a cash surplus that could be redistributed to investors in form of risk-free cash income. With respect to the investor-specific parameters as shown in Figure 4 only the parameter of risk aversion determines the optimal demand. The initial endowment does not influence the optimal quantities.

Lastly, we want to determine the unique riskless rate where the equilibrium price is the same as in the setting with divergent interest rates. The result is surprising. If one wants to arrive at the same price $\left(S_{0}=8.3113\right)$ when deposit and borrowing rates are equal this requires a rate of $r^{*}=2.4933 \%$ ! This is far afield from both $5 \%$ and $10 \%$. Also, wrongly using $r^{*}=5 \%$ or

${ }^{21}$ Again, calculations can be found in Appendix B 
$r^{*}=10 \%$ gives values of the risky asset $S_{0} \in[7.7441,8.1129]$. This value is not even close to the correct value above.

In the above examples we have used fixed deposit and borrowing rates. Finally, we will show using a graph how optimal demand as well as unique interest rates vary if we change the borrowing rate. The figure 6 shows our results as a function of the spread $r^{\mathrm{b}}-r^{\mathrm{d}}$. The graph of the unique interest rate reveals an interesting pattern. For spreads $[0 \%, \approx 3 \%]$ the interest rate of the equilibrium with a unique rate would be negative. We have argued that such a situation is not consistent in our model. Therefore, the only conclusion to be drawn is that for those spreads there is no equilibrium such that the price of the risky asset is the same as in the model with divergent interest rates (the graphs show those negative interest rates using a dotted line).

Figure 6: Optimal demand and unique interest rate as a function of the spread $r^{\mathrm{b}}-r^{\mathrm{d}}$.

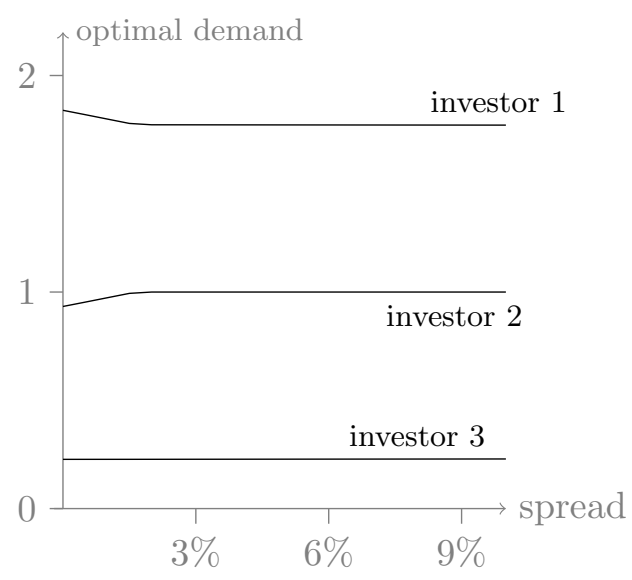

(a) Optimal demand.

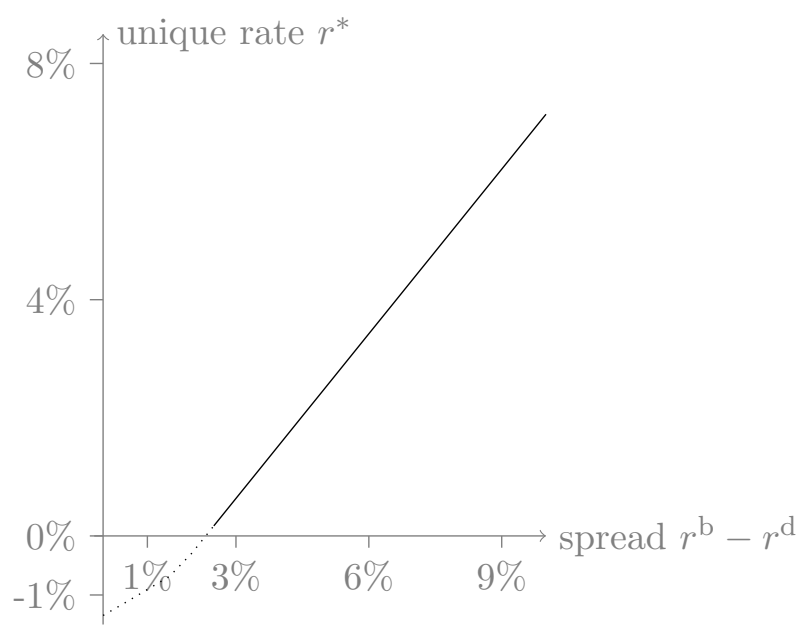

(b) Unique interest rate.

\section{Conclusion}

Theoretical flaws in the use of common standard asset pricing models (such as the CAPM) are well-known in literature. This paper deals with an additional objection that has been neglected in literature so far: divergent risk-free interest rates on borrowing and depositing. In contrast to most of the objections that are sometimes hard to remedy, this paper presents a simple framework with closed-form solutions for investors' portfolio choice 
that take into account divergent borrowing and deposit rates. We show that this extension must be handled with care, since arbitrage opportunities can occur easily whenever market participants simultaneously borrow and lend money at divergent rates. Therefore, in our model only one institution is allowed to act as a bank and to grant risk-free credits and financial investments. We find that this bank necessarily earns a positive cash surplus which is assumed to be redistributed to the market participants.

Our results are the following: Firstly, the optimal demand for risky assets depends on the investor's initial endowment and is therefore investor-specific even if a homogeneous degree of risk aversion and homogeneous expectations are assumed. Moreover, the redistribution of the bank's surplus influences the optimal allocation of an individual's resources.

In the context of a general equilibrium analysis we were able to show, that an equilibrium always exists, but is not necessarily unique.

Finally, we investigated the relationship between the case of divergent interest rates and the case of a unique interest rate that will lead to the same price of the risky asset. It seems reasonable to assume that a model with a unique interest rate will generate the same equilibrium asset prices as those generated by a model based on divergent interest rates, as long as this unique interest rate is determined as a weighted average of the deposit and borrowing rate. However, we showed that this obvious assumption does not generally hold true. Instead, such a procedure may result in severe mispricing.

It is only in those circumstances in which every investor trades, the bank's proceeds are distributed equally among investors and the number of investors is rather large, that the unique interest rate approximately equals a weighted average of the deposit and borrowing rate. Modern financial markets are rather large with respect to the number of participiants, so the assumption of a large $I$ does not seem to be far-fetched. Furthermore, if we interpret the redistribution mainly as the provision of public goods one can argue that every investor is (more or less) endowed with the same parameter $\omega_{i}$. Seen in this light, the assumption that every investor receives the same redistribution is realistic. More problematic is the requirement that every investor trades; as recent research has shown this is not the case and was even described as the "nonparticipation puzzle" (see, for example, Mankiw and Zeldes (1991) who show that a large fraction of households hold no equity). If this requirement could be omitted the main message of our paper is summarized as follows: Textbook examples with only a few investors where borrowing and deposit rates are different should be handled with care. But in real markets with lots of investors it is fairly unprob- 
lematic to replace the divergent interest rates with a (weighted) average and simplify the model in such a way that only a unique interest rate exists. Further research discussing divergent interest rates should focus on the nonparticipation problem.

\section{Appendix A. Derivation of Individual Optimal Demand}

An investor's objective at date 0 is to choose an admissible trading strategy that maximizes her utility according to equation (5) with

$$
\begin{aligned}
\mathrm{E}\left(C_{1 i}\right) & =n_{i} \cdot \mathrm{E}\left(S_{1}\right)+n_{i}^{\mathrm{d}} \cdot 1-n_{i}^{\mathrm{b}} \cdot 1+\omega_{i} \sum_{j}\left(n_{j}^{\mathrm{b}}-n_{j}^{\mathrm{d}}\right) \\
\operatorname{Var}\left(C_{1 i}\right) & =n_{i}^{2} \cdot \operatorname{Var}\left(S_{1}\right)
\end{aligned}
$$

Plugging these equations into the utility function (5) gives

$$
U_{i}=n_{i} \cdot \mathrm{E}\left(S_{1}\right)+n_{i}^{\mathrm{d}} \cdot 1-n_{i}^{\mathrm{b}} \cdot 1+\omega_{i} \sum_{j}\left(n_{j}^{\mathrm{b}}-n_{j}^{\mathrm{d}}\right)-\frac{a_{i}}{2} \cdot n_{i}^{2} \cdot \operatorname{Var}\left(S_{1}\right) .
$$

This function has to be maximized given the constraints (1) and (2). In addition, the investor has to obey her budget constraint in $t=0$ which reads as

$$
\bar{n}_{i} \cdot S_{0}+n_{i}^{\mathrm{b}} \frac{1}{1+r^{\mathrm{b}}}=n_{i} \cdot S_{0}+n_{i}^{\mathrm{d}} \frac{1}{1+r^{\mathrm{d}}} .
$$

Because optimization is now subject to several, partly non-linear constraints, we use the Kuhn-Tucker approach. The optimization fully reads

$$
\begin{aligned}
\max _{n_{i}, n_{i}^{\mathrm{d}}, n_{i}^{\mathrm{b}}} n_{i} \cdot \mathrm{E}\left(S_{1}\right)+n_{i}^{\mathrm{d}} \cdot 1-n_{i}^{\mathrm{b}} \cdot 1+\omega_{i} \sum_{j}\left(n_{j}^{\mathrm{b}}-n_{j}^{\mathrm{d}}\right)-\frac{a_{i}}{2} \cdot n_{i}^{2} \cdot \operatorname{Var}\left(S_{1}\right), \\
\text { s.t. } \quad n_{i}^{\mathrm{b}} \cdot n_{i}^{\mathrm{d}}=0, n_{i}^{\mathrm{b}} \geq 0, n_{i}^{\mathrm{d}} \geq 0 \\
\quad \bar{n}_{i} \cdot S_{0}+n_{i}^{\mathrm{b}} \frac{1}{1+r^{\mathrm{b}}}=n_{i} \cdot S_{0}+n_{i}^{\mathrm{d}} \frac{1}{1+r^{\mathrm{d}}} \cdot(\text { A. } 5)
\end{aligned}
$$

The constraint $n_{i}^{\mathrm{b}} \cdot n_{i}^{\mathrm{d}}=0$ can easily be incorporated into the maximization. We know that both variables cannot simultaneously be different from zero if we achieved a maximum. Hence, we can maximize twice by sequen-

tially setting the variables $n_{i}^{\mathrm{b}}$ and $n_{i}^{\mathrm{d}}$ equal to zero. If we then compare both utility values and determine the larger one we have solved the optimization problem under (2). This solution will depend on the endowment of the investor. 
We first look at the FOC for $n_{i}^{\mathrm{b}}=0$. Then the optimization problem A.5 is reduced to

$$
\begin{aligned}
\max _{n_{i}, n_{i}^{\mathrm{d}}} n_{i} \cdot \mathrm{E}\left(S_{1}\right)+n_{i}^{\mathrm{d}}+\omega_{i} \sum_{j}\left(n_{j}^{\mathrm{b}}-n_{j}^{\mathrm{d}}\right)-\frac{a_{i}}{2} \cdot n_{i}^{2} \cdot \operatorname{Var}\left(S_{1}\right), \\
\text { s.t. } \quad n_{i}^{\mathrm{d}} \geq 0, \quad \bar{n}_{i} \cdot S_{0}-n_{i} \cdot S_{0}=n_{i}^{\mathrm{d}} \frac{1}{1+r^{\mathrm{d}}} .
\end{aligned}
$$

Incorporating the budget constraint into the maximization yields (notice that $\left.S_{0}>0\right)$

$$
\max _{n_{i} \leq \bar{n}_{i}} n_{i} \mathrm{E}\left(S_{1}\right)+\left(1-\omega_{i}\right)\left(\bar{n}_{i}-n_{i}\right) S_{0}\left(1+r^{\mathrm{d}}\right)+\omega_{i} \sum_{j \neq i}\left(n_{j}^{\mathrm{b}}-n_{j}^{\mathrm{d}}\right)-\frac{a_{i}}{2} n_{i}^{2} \operatorname{Var}\left(S_{1}\right) .
$$

Denoting the Lagrange multiplier by $\lambda^{l}$ we get the $\mathrm{FOC}^{22}$

$$
0=\mathrm{E}\left(S_{1}\right)-\left(1-\omega_{i}\right) S_{0}\left(1+r^{\mathrm{d}}\right)-a_{i} n_{i} \operatorname{Var}\left(S_{1}\right)-\lambda^{l} .
$$

which can be written as

$$
n_{i}=\frac{\mathrm{E}\left(S_{1}\right)-\left(1-\omega_{i}\right) S_{0}\left(1+r^{\mathrm{d}}\right)-\lambda^{l}}{a_{i} \operatorname{Var}\left(S_{1}\right)}
$$

and

$$
\lambda^{l}\left(n_{i}-\bar{n}_{i}\right)=0
$$

This implies: if

$$
\underbrace{\frac{\mathrm{E}\left(S_{1}\right)-\left(1-\omega_{i}\right) S_{0}\left(1+r^{\mathrm{d}}\right)}{a_{i} \operatorname{Var}\left(S_{1}\right)}}_{:=n_{i}^{\mathrm{d}}} \leq \bar{n}_{i}
$$

then this $n_{i}$ is optimal (because $\lambda^{l}=0$ ). Otherwise $n_{i}=\bar{n}_{i}$ is optimal.

The case of borrowing can be handled analogously.

\footnotetext{
${ }^{22}$ Notice that this FOC is only correct if there are divergent interest rates. If deposit and borrowing can be done with the same rate the sum $\sum_{j}\left(n_{j}^{\mathrm{b}}-n_{j}^{\mathrm{d}}\right)$ will be zero and the term $\omega_{i} S_{0}\left(1+r^{\mathrm{d}}\right)$ will vanish in the equation.
} 


\section{Appendix B. Numerical Example}

Given $S_{0}=8.3113$, for investor $1 n_{1}^{\mathrm{b}}$ and $n_{1}^{\mathrm{d}}$ amount to

$$
\begin{aligned}
& n_{1}^{\mathrm{b}}=\frac{\mathrm{E}\left(S_{1}\right)-S_{0}\left(1+r^{\mathrm{b}}\right)\left(1-\omega_{i}\right)}{a_{i} \operatorname{Var}\left(S_{1}\right)}=\frac{10-8.3113(1+0.1)(1-0.2)}{1 \cdot 1}=1.7718 \\
& n_{1}^{\mathrm{d}}=\frac{\mathrm{E}\left(S_{1}\right)-S_{0}\left(1+r^{\mathrm{d}}\right)\left(1-\omega_{i}\right)}{a_{i} \operatorname{Var}\left(S_{1}\right)}=\frac{10-8.3113(1+0.05)(1-0.2)}{1 \cdot 1}=2.1458 .
\end{aligned}
$$

Since investor 1 is initially endowed with one share of the risky asset, $\bar{n}_{1}=$ $1<n_{1}^{\mathrm{b}}<n_{1}^{\mathrm{d}}$, it is optimal for her to borrow. Consequently, she buys risky asset and acts as a borrower. Thus, according to (6) she optimally demands $n_{1}^{\mathrm{d}}=1.7718$ shares.

Analogously, for investor 2 the following holds true

$$
\begin{aligned}
& n_{2}^{\mathrm{b}}=\frac{\mathrm{E}\left(S_{1}\right)-S_{0}\left(1+r^{\mathrm{b}}\right)\left(1-\omega_{i}\right)}{a_{i} \operatorname{Var}\left(S_{1}\right)}=\frac{10-8.3113(1+0.1)(1-0)}{10 \cdot 1}=0.85757 \\
& n_{2}^{\mathrm{d}}=\frac{\mathrm{E}\left(S_{1}\right)-S_{0}\left(1+r^{\mathrm{d}}\right)\left(1-\omega_{i}\right)}{a_{i} \operatorname{Var}\left(S_{1}\right)}=\frac{10-8.3113(1+0.05)(1-0)}{1 \cdot 1}=1.27314 .
\end{aligned}
$$

However, her initial endowment of 1 shares lies inbetween these numbers, $n_{2}^{\mathrm{d}}>\bar{n}_{2}=1>n_{2}^{\mathrm{b}}$. Obviously, she cannot reach either the optimal number of shares for borrowers $n^{\mathrm{b}}$ by increasing her endowment, nor the optimal value for depositers $n^{\mathrm{d}}$ by decreasing her endowment. According to (6) it is thus optimal for her to leave her initial endowment unchanged and to refrain from trading.

Finally, for investor $3 n_{3}^{\mathrm{b}}$ and $n_{3}^{\mathrm{d}}$ amount to

$$
\begin{aligned}
& n_{3}^{\mathrm{b}}=\frac{\mathrm{E}\left(S_{1}\right)-S_{0}\left(1+r^{\mathrm{b}}\right)\left(1-\omega_{i}\right)}{a_{i} \operatorname{Var}\left(S_{1}\right)}=\frac{10-8.3113(1+0.1)(1-0.9)}{1 \cdot 40}=0.22714 \\
& n_{3}^{\mathrm{d}}=\frac{\mathrm{E}\left(S_{1}\right)-S_{0}\left(1+r^{\mathrm{d}}\right)\left(1-\omega_{i}\right)}{a_{i} \operatorname{Var}\left(S_{1}\right)}=\frac{10-8.3113(1+0.05)(1-0.9)}{1 \cdot 40}=0.22818 .
\end{aligned}
$$

Both numbers are smaller than her initial endowment of one share in the risky asset, $\bar{n}_{3}=1$, which is why she sells her shares in order to maximize her utility. In doing so she invests the proceeds into riskless asset at $r^{\mathrm{d}}$ and consequently acts as a depositer. According to (6) she thus optimally holds $n_{3}^{\mathrm{d}}=0.22818$ shares.

Under the assumption of a unique interest rate, no cash surplus can be generated and redistributed. Therefore, optimal demand for the risky asset amounts to

$$
n_{i}=\frac{\mathrm{E}\left(S_{1}\right)-S_{0}(1+r)}{a_{i} \operatorname{Var}\left(S_{1}\right)}=\frac{10-8.3113(1+0.075)}{1 \cdot a_{i}} .
$$


Without any distinction of cases, the optimal demand is determined as $n_{1}=$ $1.0654, n_{2}=1.0654$ and $n_{3}=0.0266$.

\section{References}

Bamberg, G., Firchau, V., 1981. Some remarks on the aggregation theorem for divergent borrowing and lending rates, in: Bamberg, G., Opitz, O. (Eds.), Proceedings of the 6th Symposium on Operations Research: Universität Augsburg, September 7th-9th, 1981, Athenäum, Königstein/Ts.. pp. $465-476$.

Bertomeu, J., Cheynel, E., 2016. Disclosure and the cost of capital: A survey of the theoretical literature. Abacus 52, 221-258.

Brealey, R.A., Myers, S.C., 1996. Principles of Corporate Finance. 5 ed., McGraw-Hill, New York.

Brennan, M.J., 1970. Taxes, market valuation, and corporate financial policy. National Tax Journal 23, 417-427.

Brennan, M.J., 1971. Capital market equilibrium with divergent borrowing and lending rates. The Journal of Financial and Quantitative Analysis 6, $1197-1205$.

Cheng, P.L., 1980. Divergent rates, financial restrictions and relative prices in capital market equilibrium. The Journal of Financial and Quantitative Analysis 15, 509-540.

Chua, J.H., 1975. Capital Market Equilibrium with Divergent Borrowing and Lending Rates: Comments and Corrections. Working Paper No. 118. The University of Michigan. Graduate School of Business Administration, Division of Research.

Davis, S.J., Kubler, F., Willen, P., 2006. Borrowing costs and the demand for equity over the life cycle. The Review of Economics and Statistics 88, $348-362$.

Eikseth, H.M., Lindset, S., 2009. A note on capital asset pricing and heterogeneous taxes. Journal of Banking and Finance 33, 573-577.

Fisher, I., 1930. The Theory of Interest: As Determined by Impatience to Spend Income and Opportunity to Invest It. Macmillan, New York. (Reprint: Augustus M. Kelley: New York 1965). 
Hammami, Y., 2014. An empirical investigation of asset pricing models under divergent lending and borrowing rates. Financial Markets and Portfolio Management 28, 263-279.

Hirshleifer, D., Huang, C., Teoh, S.H., 2017. Model uncertainty, ambiguity aversion and market participation. http://ssrn. com/paper=2898992.

Hirshleifer, J., 1958. On the theory of optimal investment decision. Journal of Political Economy 66, 329-352.

Konrad, K.A., 1991. Risk taking and taxation in complete capital markets. The Geneva Papers on Risk and Insurance Theory 16, 167-177.

Kruschwitz, L., Löffler, A., 2009. Do taxes matter in the CAPM? Business Research 2, 171-178.

Lintner, J.V., 1965. The valuation of risk assets and the selection of risky investments in stock portfolios and capital budgets. The Review of Economics and Statistics 47, 13-37.

Litzenberger, R.H., Ramaswamy, K., 1979. The effect of personal taxes and dividends on capital asset prices: Theory and empirical evidence. Journal of Financial Economics 7, 163-195.

Löffler, A., 1996. Variance aversion implies $\mu-\sigma^{2}$-criterion. Journal of Economic Theory 69, 532-539.

Mankiw, N.G., Zeldes, S.P., 1991. The consumption of stockholders and nonstockholders. Journal of Financial Economics 29, 97-112.

Mossin, J., 1966. Equilibrium in a capital asset market. Econometrica 34, $768-783$.

Rudin, W., 1976. Principles of Mathematical Analysis. 3 ed., McGraw-Hill, New York.

Sharpe, W.F., 1964. Capital asset prices: A theory of market equilibrium under conditions of risk. The Journal of Finance 19, 425-442.

Sialm, C., 2009. Tax changes and asset pricing. The American Economic Review 99, 1356-1383. 